\title{
Rituals in gastrointestinal endoscopy at the crossroads of shaman and science
}

\section{다 (용}

\begin{abstract}
Author
Amnon Sonnenberg

Institution

The Portland VA Medical Center and the Division of Gastroenterology/Hepatology, Oregon Health \& Science University, Portland, Oregon, USA
\end{abstract}

submitted 17.2.2017

accepted after revision 2.3.2017

Bibliography

DOI https://doi.org/10.1055/s-0043-111791 |

Endoscopy International Open 2017; 05: E627-E629

(c) Georg Thieme Verlag KG Stuttgart · New York ISSN 2364-3722

Corresponding author

Amnon Sonnenberg, MD MSc, Portland VA Medical Center P3-GI, 3710 SW US Veterans Hospital Road, Portland, OR 97239, USA

Fax: +1-503-220-3426

sonnenbe@ohsu.edu

\section{ABSTRACT}

Background and aim Over the last decades, the length of time required for endoscopic procedures has greatly expan- ded. The aim of the present decision analysis is to study the interactions amongst various factors that have caused such delays and to compare the relative magnitude of their influences.

Methods Performance of gastrointestinal endoscopy is influenced by the interaction of five domains, that is, (1) patient discomfort and fear; (2) injury, disorder, and disruption; (3) rituals to reduce fear, prevent disruption, and maintain order; (4) administrators or various health providers carrying out a ritual; (5) information, knowledge, and science, which influence fear, prevent disruption, and curtail unnecessary ritualistic behavior. A Markov chain model is used to describe the interaction among the five domains. Results Overall, science exerts the strongest influence, followed by fear and ritual as distant second and third most relevant influences, respectively. Disruption and administrator exert only a minor influence on the system of mutual interactions.

Conclusions Studying patterns of ritualistic behavior during endoscopy and subjecting them to means of scientific research could help eliminate redundancy, cutting unnecessary rituals, and thus making gastrointestinal endoscopy overall more efficient.

\section{Introduction}

During my fellowship almost 40 years ago, assisted by a single nurse, I could do 14 endoscopies on a given day. Nowadays, being a far more dexterous and experienced endoscopist and being assisted by at least two nurses, I struggle to complete 10 procedures per day. Although my actual procedural times have more than halved, the examination room is hardly ever turned over in less than 45 minutes. If anesthesiology becomes involved and the endoscopy takes place in the operating room, the turnover time and the number of auxiliary personnel easily double. At each endoscopy, the physician at our institution needs to fill out eight different forms, not to mention three separate forms completed by the nurses. A lot of additional time is spent on various measures to prevent errors, and assure quality control and patient safety. Part of this peri-procedural formality resembles a ritual, using stilted language and being performed in a ceremonious fashion without generating any new information or resulting in any tangible outcomes. What are the factors that influence such behavior?

Medical procedure and invasion of the patient's privacy elicit discomfort and fear. They can also result in injury, disorder, or disruption. A ritual serves to reduce fear, prevent disruption, and maintain order. The ritual is not part of the endoscopy itself, but an act performed by someone officiated to do it, such as an administrator, nurse, physician, or the shaman in all of us. Information, knowledge, and science can influence the amount of fear, prevent disruption, and curtail unnecessary burgeoning ritualistic behavior. The five factors (fear, disruption, ritual, shaman, and science) represent the five broad domains, which interact with and influence each other. The aim of the present decision analysis is to study the interactions amongst these factors and compare the relative magnitude of their concurrent influences. 
Table 1 Markov matrix of interacting factors in the emergence of medical rituals.

\begin{tabular}{|c|c|c|c|c|c|}
\hline & Fear & Disruption & Ritual & Shaman & Science \\
\hline \multicolumn{6}{|c|}{ Markov matrix of interacting factors } \\
\hline Fear & $20 \%$ & $33 \%$ & $20 \%$ & $11 \%$ & $10 \%$ \\
\hline Disruption & $0 \%$ & $33 \%$ & $20 \%$ & $11 \%$ & $0 \%$ \\
\hline Ritual & $40 \%$ & $33 \%$ & $20 \%$ & $33 \%$ & $0 \%$ \\
\hline Shaman & $0 \%$ & $0 \%$ & $20 \%$ & $11 \%$ & $0 \%$ \\
\hline Science & $40 \%$ & $0 \%$ & $20 \%$ & $33 \%$ & $90 \%$ \\
\hline \multicolumn{6}{|c|}{ Steady-state matrix } \\
\hline Fear & $13 \%$ & $13 \%$ & $13 \%$ & $13 \%$ & $13 \%$ \\
\hline Disruption & $3 \%$ & $3 \%$ & $3 \%$ & $3 \%$ & $3 \%$ \\
\hline Ritual & $8 \%$ & $8 \%$ & $8 \%$ & $8 \%$ & $8 \%$ \\
\hline Shaman & $2 \%$ & $2 \%$ & $2 \%$ & $2 \%$ & $2 \%$ \\
\hline Science & $74 \%$ & $74 \%$ & $74 \%$ & $74 \%$ & $74 \%$ \\
\hline
\end{tabular}

\section{Methods}

A Markov chain model is used to describe the interaction among the five factors fear, disruption, ritual, shaman, and science in gastrointestinal endoscopy [1-4]. The top part of - Table 1 contains the Markov matrix of the interactions between the five factors. Each factor depicted as a row can exert some influence on itself or any of the other four factors also listed as column headings. Each influence is graded between 0 and $100 \%$. According to the probability laws governing Markov chains, the sum of all influences acting on an individual factor (contained in a single column) must add up to $100 \%[1,2]$.

The strength of interactions among the five factors has been estimated based on personal experience. For instance, fear is assumed to be equally assuaged by ritual or science but also, to a lesser degree, to be self-perpetuating. Disruption is assumed to be equally affected by fear, disruption, and ritual. Ritual is assumed to be equally affected by all factors, including itself (meaning that a ritual can become self-perpetuating and gain some life of its own). The position of the shaman is assumed to be mostly influenced by science and the need for ritual and, to a lesser degree, by all other factors. Lastly, science is to a small degree driven by needs to alleviate fear, but mostly by forces within science itself. In a subsequent sensitivity analysis, these probability values become varied over a broad range.

The steady-state of a Markov matrix is calculated by multiplying the matrix many times ( $n>16)$ with itself [1-4]. Such calculation is easily performed on an Excel spreadsheet using its built-in MMULT array function. In the steady-state matrix, all row elements eventually become identical. They depict the relative strength of influence of the individual factor on the overall model.

\section{Results}

The bottom part of $>$ Table 1 shows the steady-state of the Markov matrix with its identical row elements representing the relative influence of the corresponding factor in the model. Of all factors, science exerts the strongest influence, followed by fear and ritual as distant second and third most relevant influences, respectively. Disruption and shaman exert only a minor influence on the system of mutual interactions. This pattern remains largely insensitive to variations in the strengths of individual influences chosen for the initial Markov matrix. However, creating new or eliminating existing interactions between the five factors and introducing new additional factors can ultimately change the outcome of the model. The overall pattern suggests that updating and expanding the scientific basis underlying gastrointestinal endoscopy would be the most effective means for change and betterment of its performance.

\section{Discussion}

Over the last decades, the length of time required for endoscopic procedures has greatly expanded. Administrative redundancies and filling of various paper and electronic forms have been put in place because of the medicolegal climate in which most physicians operate nowadays. These patterns are likely to be true in Europe and North America, but may not apply to other countries where endoscopy is less regulated or physicians are culturally less concerned about legal issues. In addition, medicine has become more complex not only in its demands for documentation but also with respect to what types of information can be documented. For example, when previously blood pressure and pulse constituted the only parameters measured, nowadays we also record pulse oximetry, electrocardiogram, and capnography.

The American Society of Gastrointestinal Endoscopy (ASGE) has published multiple guidelines on the proper conduct of 
endoscopic procedures. The implied benefit of such guidelines is that they generally improve the quality and safety of endoscopy $[5,6]$. Similar guidelines have been generated by the European Society of Gastrointestinal Endoscopy (ESGE) [7, 8]. Most endoscopists also operate within the boundaries set by hospital policies and bylaws. The mantra of quality improvement and increased safety is rarely, if ever, challenged [9], but how do we balance the perceived improved safety or quality of endoscopy with the extra effort and costs of delivering them? The true benefits of recommended and practiced quality measures have gone largely untested [10]. We need research and science to establish the cost-effectiveness of our practice and to reject low-value rituals.

Some ritual in the performance of invasive procedures may be unavoidable, even desirable or beneficial in easing patient fears, discomfort, and assuring quality control. It has been pointed out that rituals are important not only for the patient but also for the physician and other healthcare providers [11, 12]. The present model is not meant to belittle their relevance altogether, but rather to suggest that studying patterns of our ritualistic behavior and subjecting them to means of scientific research could help eliminate redundancy, remove unnecessary rituals, and thus make endoscopy overall more efficient.

\section{Competing interests}

None

\section{References}

[1] Higgins ], Keller-McNulty S. Concepts in probability and stochastic modeling. Duxbury Press; 1995

[2] Ross SM. Introduction to probability models.7th edn. San Diego, CA: Harcourt; 2000: $499-548$

[3] Sonnenberg A. Transposed Markov matrix as a new decision tool of how to choose among competing investment options in academic medicine. Comput Math Methods Med 2009; 10: 1 - 7

[4] Sonnenberg A, Naugler WE. Models of influence in chronic liver disease. Liver Int 2010; 30: $718-724$

[5] Rizk MK, Sawhney MS, Cohen J et al. Quality indicators common to all GI endoscopic procedures. Am J Gastroenterol 2015; 110: 48-59

[6] Calderwood AH, Chapman FJ, Cohen J et al. Guidelines for safety in the gastrointestinal endoscopy unit. Gastrointest Endosc 2014; 79: $363-372$

[7] Bisschops R, Areia M, Coron E et al. Performance measures for upper gastrointestinal endoscopy: a European Society of Gastrointestinal Endoscopy (ESGE) Quality Improvement Initiative. Endoscopy 2016; 48: $843-864$

[8] Kaminski MF, Thomas-Gibson S, Bugajski M et al. Performance measures for lower gastrointestinal endoscopy: a European Society of Gastrointestinal Endoscopy (ESGE) Quality Improvement Initiative. Endoscopy 2017; 49: 378-397

[9] Sonnenberg A. Arguments against costly quality assurance. Gastrointest Endosc 2011; 72: 567 - 569

[10] Prasad VK, Cifu AS. Ending medical reversal - improving outcomes, saving lives. Baltimore, MD: Johns Hopkins University Press; 2015

[11] Hosamani P, Verghese A. Annals for hospitalists inpatient notes - rituals in chaos, the sacred in the profane. Ann Intern Med 2017: DOI: 10.7326/M16-2737

[12] Montross-Thomas LP, Scheiber C, Meier EA et al. Meaningful rituals: A way to increase compassion and decrease burnout among hospice staff and volunteers. J Palliat Med 2016; 19: 1043 - 1050 